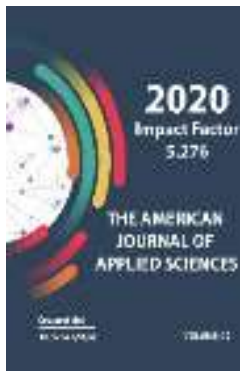

Journal Website: http://usajournalshub.c om/index,php/tajas

Copyright: Original content from this work may be used under the terms of the creative commons attributes 4.0 licence.

\section{Institutional Transformations In The Fruit And Vegetable Industry And Their Impact On Mitigating The Consequences Of The Coronavirus Pandemic In Uzbekistan}

\title{
ABSTRACT
}

\author{
Ikromiddin Kutbiddinovich Sirojiddinov \\ Candidate Of Economic Sciences, Associate Professor, \\ Namangan Civil Engineering Institute, Uzbekistan \\ Kamoliddin Ikromiddinovich Sirojiddinov \\ Candidate Of Economic Sciences, Associate Professor, \\ Namangan State University, Uzbekistan
}

The article examines the issues of institutional transformations in the fruit and vegetable industry and strengthening the market orientation of production at the current stage of socio-economic development.

\section{KEYWORDS}

Economic sense, market economy, private property, agricultural sector, coronavirus pandemic, the nutritional and energy properties, the food security

\section{INTRODUCTION}

As you know, an institution in the economic sense means a certain form through which economic relations are realized. For example, in a market economy, the decisive institution is the institution of private property, which means ownership of wealth based on economic responsibility and interest. Through this institution, real economic responsibility and interest in concrete results are achieved. In the fruit and vegetable industry of 
Uzbekistan, economic entities are organized mainly in the form of private property. However, the lack of private ownership of land to a certain extent weakens the role of private property relations in this sector of the economy. On the other hand, in recent years, the pace of socio-economic reforms has accelerated, and the social orientation of the economy is strengthening. From this point of view, two important facts can be noted: the very first task of the agricultural sector is to ensure the food security of the country and the official recognition of the existence of poverty in the country, as well as the need to overcome it. In the context of the coronavirus pandemic, these problems manifest themselves even more clearly. Their solution is to a certain extent related to the development of the fruit and vegetable industry.

\section{THE MAIN FINDINGS AND RESULTS}

World experience shows that only market agriculture is capable of providing a sufficient abundance of food products and government support for agriculture should be carried out mainly by market methods, the widespread introduction of market institutions. Poverty is concretely expressed in the absence of real access to the corresponding benefits, including underconsumption of food. Thus, the two facts are interconnected.

The coronavirus pandemic has had a significant impact on the structure of foreign economic relations between countries, on the structure of exports and imports. The importance of food exports has noticeably increased. Of course, this was important before. In a pandemic, not only the nutritional and energy properties of foods have become especially important, but also their value in terms of their impact on human immunity. These factors open up new opportunities for the export of fruit and vegetable products, their producers gain access to large sales markets. From the standpoint of institutionalism, the institutional structure of a particular branch of the economy is crucial for its effective functioning. It is no coincidence that in the years of independence, agrarian reforms in Uzbekistan took place in exactly this direction: the massive provision of household plots to the rural population, the transformation of collective farms into shirkat farms, the transformation of the latter into farms, and multiple transformations of the latter. All this happened until 2017 and, however, in fact, modern agriculture was never created, technical and technological progress did not affect the most important sectors of the agricultural sector. In our opinion, the reason was that the created institutions, in their essence, had to work in conditions of market freedom, and such freedom was not given to agricultural producers.

Recently, many researchers have noted the formation of Uzbekistan as a very serious subject of the world economy, the development of which will have a significant impact not only on the neighboring countries. These achievements are critically due to the consistent implementation of market reforms. At the same time, due to historical and some other circumstances, market transformations affected agriculture least of all sectors of the economy. Until recently, the bulk of the irrigated land, moreover the most fertile, was legislatively fixed for sowing cotton, moreover, not by the laws themselves, but by bylaws that directly contradicted the provisions of the Constitution of the country. For example, the Law on Farming gives the farmer the freedom to choose crops, and the bylaws give the local government the right to take the land away from the farmer if he does 
not plant cotton on the land. Farmers were required to grow this particular crop and sell the resulting products to the state at fixed prices that did not cover the real costs of producers. From time to time there was a reorganization of agricultural producers (optimization). But the real economic conditions remained the same and, accordingly, the economic situation in agriculture did not practically improve. With the introduction of clusters, the situation in cotton growing has significantly changed for the better, yields and incomes of farmers have increased. However, it was not possible to completely overcome the inertia, by the beginning of 2020, the debt of processing enterprises to farmers for the delivered raw cotton amounted to 800 billion soums and it was repaid only after the intervention of state bodies.

In Uzbekistan, the real liberalization of economic relations in the agricultural sector of the economy is associated with the adoption of the Action Strategy for the Further Development of the Republic of Uzbekistan in 2017-2021, which, in its content and focus, provides for the creation of a modern competitive economy. It also outlines the deepening of structural changes in agriculture and its consistent development, further strengthening of the country's food independence, expansion of the production of environmentally friendly products, and a significant increase in the export potential of the agricultural sector. This should be done by optimizing the acreage by reducing the area of cotton and grain crops, placing potatoes, vegetables, fodder and oilseeds, new intensive orchards and vineyards on the freed up areas (1).

Obviously, without the liberalization of agrarian relations, the course of modernizing the production of this sector will most likely be declarative, since it is the material interests of producers that are the driving force in any sector of the economy. On the other hand, as President of the country Sh. M. Mirziyoyev has repeatedly pointed out, the ultimate goal of the reforms is to achieve a decent standard of living for the country's population. Therefore, agriculture in Uzbekistan is increasingly focused on ensuring the country's food security and the well-being of the rural population. The decree of the President of the Republic of Uzbekistan "On measures to further ensure the food security of the country" outlined further actions necessary to fully meet the population's demand for highquality food products available to the population (2).

An important measure in this direction was the specialization of 55 regions (tumans) of the country in the production of fruits and vegetables. They will have specialized farms. Such farms will operate in other regions as well. The significance of this measure lies in the fact that the monopoly position of cotton growing is abolished in the competition between agricultural crops to place them on sown areas. The placement of crops will take place according to the market principle, that is, according to the degree of profitability for producers. In addition, private household farms and family dekhkan farms are traditionally focused on gardening, vegetable growing and viticulture. The undertaken institutional changes must create the necessary conditions for increasing their marketability.

In the context of the coronavirus pandemic in 2020, 86 clusters and 125 cooperatives have been organized to accelerate the processes of agro-industrial integration in the fruit and vegetable industry. The activities of these structures should contribute to increasing the material interest of producers in the 
production of competitive food products that are in demand on the domestic and foreign markets. Clusters and cooperatives must organize not only the sale, but also its storage and processing, which will create a value chain in the industry. All this will give a tangible socio-economic effect.

It is known that it is in a free market that business entities are by their nature most receptive to innovation. However, all this should be supported by positive trends in technological renewal, the rapid growth of lending by banks to business entities in the industry, and a decrease in the tax burden on private business. Therefore, financing of the production infrastructure by the state is expanding; a new market infrastructure is being created for the sale of the industry's products, which orientates the industry to meet the sustainable demand for products in the domestic and foreign markets.

In the context of the coronavirus pandemic, food security, as well as export orientation is becoming the basic points in the development of the agricultural sector. It is important not only to achieve an appropriate level of food consumption, but also to ensure sustainable and guaranteed production of basic types of food products in the country. Uzbekistan does not have transport communications that go directly to the world's waterways. Therefore, in crisis situations here, agriculture must provide specific volumes of certain types of food products, i.e., not only the total volume of agricultural production is important, but also its structure. So in 2020, it is planned to grow potatoes on an area of 130 thousand hectares (on the main areas, on the grain areas released after grain and on the household plots of the population), which will make it possible to obtain products in the amount of 2.9 million tons. In April 2020, the export of early potatoes amounted to 65 thousand tons.

Note that at present, Uzbekistan has fully covered the needs for food grains through its own production. Vegetable growing and horticulture are developing, which not only provide domestic needs, but are also largely aimed at export.

According to the recommendations of the World Health Organization, the consumption of fruits and vegetables for an adult is 400 grams per day. According to this indicator, the diet of the inhabitants of Uzbekistan five times exceeds this norm, which is also due to the historical traditions of national food consumption.

In the context of a coronavirus pandemic, the task of ensuring and maintaining food security is set broader and deeper, i.e. in the following areas:

- Production of the most important types of products in stable volumes, its steady increase;

- Competitiveness of products in the domestic and foreign markets, preservation and strengthening of export orientation;

- Increasing the efficiency of production based on innovative development (new technologies and agricultural technology, variety change, introduction of the production of organic products, water and energy saving, higher farming culture);

- Ensuring the harmonization of the development of the fruit and vegetable industry with environmental requirements.

No less important is the task of ensuring the well-being of the rural population and overcoming poverty. Therefore, the state has taken measures to support the traditionally existing institution of personal household plots of the population. In Uzbekistan, their 
number is 4.5 million and they own 435 thousand hectares of land. On April 15, 2020, a Resolution of the President of the Republic of Uzbekistan was adopted on the effective use of land of dekhkan farms and household plots of the population and the systematic organization of sowing. In 2020, 300 billion soums of state budget funds and 100 billion soums of loans will be allocated to support them. In addition, the state allocates 600 billion soums for the construction of lightweight greenhouses. In 2020, the production of fruit and vegetable products in this sector will double.

As part of these measures, 1,000 lightweight greenhouses were built and handed over to rural families in Chartak district of Namangan region, where it is possible to get three harvests a year. The family's income from the greenhouse is 30-40 million soums a year, and this helps to overcome poverty. 13 billion soums were spent on the construction of these greenhouses, of which 6.7 billion soums are state subsidies and 6.3 billion soums are preferential bank loans. With the normal functioning of the greenhouse, an individual family has a real opportunity to repay the bank loan amount (6.3 million soums) after the first year. This project is supported by other institutional measures. A cluster is organized here, which is headed by a private entrepreneurial structure. It provides the greenhouse owners with seeds, purchases their products on a contractual basis, and organizes agronomic services and consultations, as well as the supply of plant protection products. A training center for agribusiness is organized here. In 2020, the cluster intends to export products for $1 \mathrm{mln}$. US dollars, and in the future to bring it up to 5 million dollars.

In the Fergana region, 20 clusters and 125 fruit and vegetable cooperatives are being organized with the allocation of 10840 hectares of land for them. In 2020 - 2021, 172 investment projects worth 253.4 billion soums are being implemented in them.

For producers of most types of agricultural products, the demand from processors is of decisive importance. On July 29, 2019, the Resolution of the President of the Republic of Uzbekistan "On additional measures for the further development of in-depth processing of agricultural products and food industry" was adopted. It provides for the implementation of 174 investment projects for the processing of agricultural products, as well as 24 large investment projects for the production of import-substituting products based on local raw materials, which should lead to a significant increase in demand for agricultural food raw materials (3). Growing demand and real competition from raw material buyers should provide significant economic benefits for producers and stimulate production.

In Uzbekistan, in particular, in the regions of the Fergana Valley, there are favorable economic and organizational conditions:

a. Historical traditions, agro-technical culture and skills of growing fruit and vegetable crops and grapes are preserved and continue in households;

b. There are specialized farms and dekhkan farms in this direction;

c. There is an acceleration of agro-industrial integration in the production of vegetables, fruits and grapes (farmers strive to process products on their own farm, mini technologies are spreading);

d. The agrotechnical and technological renewal of the industry has begun;

e. The volume of lending to farms and dekhkans, rural family businesses is expanding;

f. A sparing taxation regime is introduced; 
g. The production infrastructure of agriculture is mainly financed by the state;

h. Developing market infrastructure for the sale of industry products;

i. The presence of demand for products in the domestic and foreign markets;

j. The products of the industry are competitive in the domestic and foreign markets in terms of cost and consumer qualities (4).

\section{CONCLUSION}

The successful development of agriculture, including the production of fruit and vegetable products, is based on the availability of legal (inviolability of private property, observance of the rights of agricultural producers, organizational and legal norms), organizational and institutional (the presence of state and non-state institutions that support agricultural producers), economic (the presence of economic entities with necessary amounts of capital), financial (the ability to attract financial resources from other spheres and industries, state financial support), human resources (training and retraining of personnel), research and development (scientific research, breeding work) prerequisites, market infrastructure and, which is also important, preserving national traditions of growing food crops, respecting dekhkan labor. In Uzbekistan, agricultural reform and institutional restructuring implies further strengthening these prerequisites.

\section{REFERENCES}

1. "On the Strategy of Actions for the Further Development of the Republic of Uzbekistan". Decree of the President of the Republic of Uzbekistan, February 7, 2017. - The People's Word, February 8, 2017.

2. Decree of the President of the Republic of Uzbekistan "On measures to further ensure the country's food security." http://www.lex.uz/ -

3. "On additional measures for the further development of in-depth processing of agricultural products and the food industry." Resolution of the President of the Republic of Uzbekistan, July 29, 2019. - The People's Word, July 30, 2019.

4. Sirozhiddinov I.K., Botirova R.A. Opportunities for the development of export of fruits and vegetables in the region. - Actual challenges of modern science. Collection of scientific papers. Issue 11 (31). Part I // PereyaslavKhmelnitsky, 2018. - pp. 82 - 85. 